\title{
Seismic stability of tall retaining walls with traffic surcharge
}

\author{
C. Onisiphorou \\ Department of Civil Engineering, Frederick University, Cyprus
}

\begin{abstract}
Retaining walls are commonly used in engineering practice for the retaining of soil masses that would otherwise be unstable. However, earthquake induced forces may trigger an instability or cause failure for a retaining wall. This can have major consequences for the case of tall retaining walls subjected to heavy traffic, and is thus the focus of this work. The present paper concentrates on the investigation of earthquake loading on tall retaining walls supported by an anchor force. The combined surcharge and ground motion effects resulting from earthquakes will be examined. A limit equilibrium model approach is used based on Eurocode 7, and the principles of Eurocode 8 with relevance to retaining structures are also adopted. A graphical solution is developed for the practicing engineer for the stability assessment of tall retaining walls under the combined effect of traffic surcharge and earthquake induced motion. Using simple charts, a stability factor is determined for the retaining wall.
\end{abstract}

Keywords: seismic load, retaining walls, earthquake resistance, code design, Eurocodes, stability, surcharge load, graphical solution.

\section{Introduction}

The design of earth retaining structures is important for minimizing hazards from ground failures or slope movement. Retaining structures must also be able to resist earthquake loading, resulting from strong ground movement in earthquake prone regions. Eurocode 8: Part 5 [1] addresses this issue by devoting a section on the earthquake resistant design of retaining structures, while the fundamental methods for stability considerations of retaining structures are included in EC7: Part 1 [2]. Both of these documents were adhered to, in the duration of the present work, as the author aims to follow through the recommended design procedure. 
The attention of the present paper though is focused on the seismic loading of tall reinforced concrete retaining walls, subjected to surcharge loading. A spreadsheet algorithm is developed and implemented for varying earthquake conditions and wall heights. Actions and resistances on the retaining structure are determined based on Eurocode methodology. The stability criteria and earthquake resistance of the retaining wall are examined and assessed based on Ultimate Limit State checks.

\section{Wall geometry and ground conditions}

\subsection{Geometrical data}

The geometry of the retaining structure is calculated in terms of the total wall height, $H$. The values of foundation thickness $\left(t_{f}\right)$, foundation breadth $(B)$, toe width $\left(B_{l}\right)$ and heel width $\left(B_{2}\right)$ are given in table 1 in parametric form. The stem thickness $\left(t_{s}\right)$ is kept constant at $0.4 \mathrm{~m}$. These parametric relationships are based on current practice dimensioning and also suggested dimensions from available literature, e.g. Bowles [3]. The depth of resisting soil $(D)$ in front of the wall is taken conservatively equal to the foundation thickness, and so no overdig is assumed. For the purpose of the current work, the height of the wall will be the only input geometrical parameter. The analysis will consider the cases of $H=6 \mathrm{~m}$, $7 \mathrm{~m}, 8 \mathrm{~m}, 9 \mathrm{~m}$ and $10 \mathrm{~m}$.

Table 1: $\quad$ Wall geometry.

\begin{tabular}{|l|c|}
\hline \multicolumn{1}{|c|}{ Geometry data } & Value \\
\hline Total Wall Height $(H)$ & $\mathrm{H}$ \\
\hline Stem thickness $\left(t_{s}\right)$ & $0.40 \mathrm{~m}$ \\
\hline Foundation thickness $\left(t_{f}\right)$ & $0.10 \mathrm{H}$ \\
\hline Foundation width $(B)$ & $0.60 \mathrm{H}$ \\
\hline Toe width $\left(B_{1}\right)$ & $0.25 \mathrm{H}$ \\
\hline Heel width $\left(B_{2}\right)$ & B-B $_{1}-\mathrm{t}_{\mathrm{s}}$ \\
\hline Depth of resisting soil $(D)$ & $\mathrm{t}_{\mathrm{f}}$ \\
\hline
\end{tabular}

\subsection{Soil profile}

It is important to achieve good compaction of the backfill material behind a retaining structure, and also to have as much continuity as possible with the existing soil mass. Therefore, knowledge of the natural soil variability is needed. However, since the focus of the analysis is on establishing stability criteria for the structure, the soil profile is kept simplified, assuming a homogenous and isotropic retained backfill or naturally retained soil.

The soil profiles assumed for the current work are: (a) cohesionless backfill of unit weight $\gamma=17 \mathrm{kN} / \mathrm{m}^{3}$ and friction angle $\varphi=30^{\circ}$, and (b) cohesionless backfill of unit weight $\gamma=19 \mathrm{kN} / \mathrm{m}^{3}$ and friction angle $\varphi=35^{\circ}$. The same properties are assumed for the resisting soil in front of the wall. 
The wall-soil friction angle, $\delta$, is taken as $\delta=2 / 3 \varphi$ for the active state and $\delta=0^{\circ}$ for the passive state (i.e. no friction is assumed in passive conditions). The wall inclination to the vertical, $\psi$, is $90^{\circ}$ and the inclination of the backfill, $\beta$, is $0^{\circ}$. Furthermore, it is assumed that the water table is below the footing of the retaining wall, therefore no water forces are considered in the analysis.

\section{Actions and resistances based on EC8}

\subsection{Earth pressures and seismic load}

The active and passive earth pressures from the ground are calculated based on limit equilibrium models, as suggested by Frank et al. [4]. The active earth pressure is considered as an unfavourable geotechnical action, while the passive earth pressure is taken as a resistance. The seismic effect is introduced using the method recommended in Annex E of EC8: Part5 [1]. All the forces acting on the wall-anchor-soil engineering system are shown in fig. 1.

The design seismic earth pressures are given by equation:

$$
E_{\text {aed,ped }}=\gamma\left(1 \pm k_{v}\right) K_{\text {aed,ped }} H^{2} / 2
$$

The earth pressure coefficients $K_{\text {aed }}, K_{\text {ped }}$ (static and dynamic) are based on the well known Mononobe-Okabe equations, where,

$$
K_{a e d}=\frac{\sin ^{2}\left(90^{\circ}+\varphi_{d}-\theta\right)}{\cos \theta \sin \left(90^{\circ}-\theta-\delta_{d}\right)\left[1+\sqrt{\frac{\sin \left(\varphi_{d}+\delta_{d}\right) \sin \left(\varphi_{d}-\theta\right)}{\sin \left(90^{\circ}-\theta-\delta_{d}\right)}}\right]^{2}}
$$

and

$$
K_{p e d}=\frac{\sin ^{2}\left(90^{\circ}+\varphi_{d}-\theta\right)}{\cos \theta \sin \left(90^{\circ}+\theta\right)\left[1-\sqrt{\frac{\sin \varphi_{d} \sin \left(\varphi_{d}-\theta\right)}{\sin \left(90^{\circ}+\theta\right)}}\right]^{2}}
$$

In both cases, the angles $\beta=0^{\circ}$ and $\psi=90^{\circ}$ have already been substituted, while $\delta_{d}=0^{\circ}$ for the passive earth pressure case. These equations have commonly been used by researchers, e.g. Sica et al. [5], Choudhury et al. [6], giving a more than adequate modelling of seismic performance for retaining walls, assuming a planar failure surface. However, this may be misleading for other geotechnical structures, such as earth dams, where a curved failure surface is more likely to occur, as emphasized by Sica et al. [5].

The horizontal seismic coefficient, $k_{h}$, takes the values of $0.15,0.20$ and 0.25 for the analysis (representing the three seismic zones in Cyprus), while the vertical seismic coefficient, $k_{v}$, is taken as $0.33 k_{h}$. More severe ground motions will be investigated as well for $k_{h}=0.30$ and 0.35 . These seismic coefficients are used in eqn. (4) below to calculate the angle $\theta$ in eqns. (2) and (3).

$$
\theta=\tan ^{-1}\left(\frac{k_{h}}{1 \mp k_{v}}\right)
$$


The most adverse earthquake direction is presented in the results. It should be emphasized that both horizontal and vertical components of the seismic active design force are taken into account in the analysis. Koseki et al. [7] suggest a modified method for calculating earth pressures at high seismic loads but for the scope of this work, the simplified EC8 method is adopted.

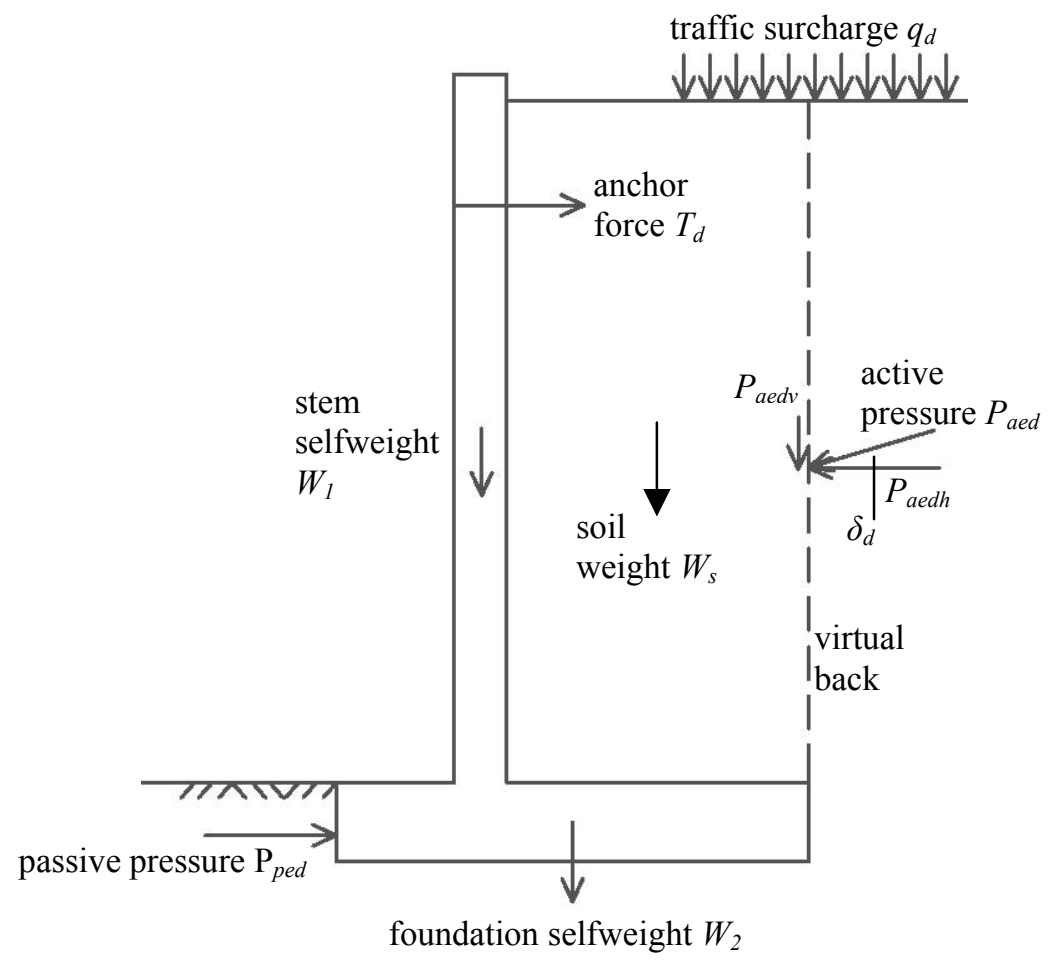

Figure 1: $\quad$ Forces acting on the wall.

\subsection{Surcharge load and anchor force}

The surcharge will be a vehicle load on the active side of the wall, therefore increasing the total force acting on the wall. A constant value of $q=10 \mathrm{kN} / \mathrm{m}^{2}$ is assumed, based on data from Reynolds et al. [8]. This will be unchanged for all cases of earthquake loading and will be considered as an unfavourable geotechnical action, even though a small portion vertically above the heel width will act as favourable and should not be included (Simpson and Driscoll [9]). The variation of surcharge intensity has been investigated in other studies (Caltabiano et al. [10]).

Due to the height of the wall an anchor force, $T$, may be necessary for the stability of the wall, ensuring a reasonable factor of safety. In the same way as for the surcharge load, the anchor force will also be assigned a constant value equal to $150 \mathrm{kN} / \mathrm{m}^{2}$ for all cases to be investigated. There is no need to consider 
the point of application of this anchor force at the moment, as only the GEO ULS check concerning sliding stability will be examined.

\section{Stability analysis}

The methodology for assessing the seismic resistance of retaining walls is based on design code EC8: Part 5 [1]. For seismic design situations, the partial factors for actions and resistances should be taken equal to 1.0 , as recommended by the National Annex to EC7 [11]. Therefore, for GEO and STR Ultimate Limit State checks, the Design Approach 3 (DA-3) is suitable for earthquake resistant design, where partial safety factors are applied to the material properties (Fardis et al. [12]).

For the current work, a partial factor of $\gamma_{\varphi}=1.25$ is applied to $\tan \varphi$, and a partial factor of 1.0 to $\gamma$ (National Annex to EC8 [13]). The surcharge load is increased by a partial factor of $\gamma_{Q}=1.3$, as it is assumed to be an unfavourable variable load in the selected design approach DA-3.

In the Ultimate Limit State design, a number of stability checks must be considered relating to actions from the ground (GEO), actions resisted by structural components (STR), and equilibrium conditions (EQU) among others. The present work will focus on the sliding stability requirement (in the GEO ULS group) for various earthquake magnitudes and different wall heights. This is just one of the GEO ULS checks introduced by EC8.

Table 2: $\quad$ Selected calculations for ULS requirements.

\begin{tabular}{|c|c|c|c|c|c|c|}
\hline & \multicolumn{4}{|c|}{ variation of wall height } & $k_{h}=0.20$ & higher $\varphi$ \\
\hline$H(\mathrm{~m})$ & 6 & 7 & 8 & 9 & 9 & 9 \\
\hline$\varphi_{d}\left(^{\circ}\right)$ & 24.8 & 24.8 & 24.8 & 24.8 & 24.8 & 29.3 \\
\hline$\gamma\left(\mathrm{kN} / \mathrm{m}^{3}\right)$ & 17 & 17 & 17 & 17 & 17 & 19 \\
\hline$\delta_{d}\left({ }^{\circ}\right)$ & 16.5 & 16.5 & 16.5 & 16.5 & 16.5 & 19.5 \\
\hline$k_{h}$ & 0.25 & 0.25 & 0.25 & 0.25 & 0.20 & 0.25 \\
\hline$k_{v}$ & 0.083 & 0.083 & 0.083 & 0.083 & 0.066 & 0.083 \\
\hline$K_{\text {aed }}$ & 0.56 & 0.56 & 0.56 & 0.56 & 0.46 & 0.48 \\
\hline$K_{\text {ped }}$ & 1.95 & 1.95 & 1.95 & 1.95 & 2.07 & 2.40 \\
\hline$P_{\text {aedh }}(\mathrm{kN} / \mathrm{m})$ & 178 & 242 & 316 & 400 & 324 & 381 \\
\hline$P_{a e d v}(\mathrm{kN} / \mathrm{m})$ & 53 & 72 & 94 & 119 & 96 & 135 \\
\hline$P_{\text {ped }}(\mathrm{kN} / \mathrm{m})$ & 6 & 9 & 11 & 15 & 15 & 20 \\
\hline$q_{d}\left(\mathrm{kN} / \mathrm{m}^{2}\right)$ & 13 & 13 & 13 & 13 & 13 & 13 \\
\hline$T_{d}(\mathrm{kN} / \mathrm{m})$ & 150 & 150 & 150 & 150 & 150 & 150 \\
\hline$\Sigma F_{v}(\mathrm{kN} / \mathrm{m})$ & 372 & 503 & 653 & 824 & 801 & 899 \\
\hline$R_{e d}(\mathrm{kN} / \mathrm{m})$ & 267 & 308 & 355 & 409 & 403 & 488 \\
\hline$E_{e d}(\mathrm{kN} / \mathrm{m})$ & 221 & 293 & 374 & 465 & 378 & 437 \\
\hline$N_{s}$ & 1.21 & 1.05 & 0.95 & 0.88 & 1.07 & 1.34 \\
\hline
\end{tabular}


The analysis is presented in tabular form in table 2 for some selected cases, in a similar format as presented by Simpson et al. [9], and is shown in sequence. Using the appropriate partial factors for the material, the design values have been calculated, based on the assumed characteristic values of section 2.2 above. The active and passive earth pressure coefficients, which include the dynamic effect are calculated by the eqns. (2) and (3). The seismic active and passive earth pressures are obtained using eqn. (1) following the procedure recommended by Annex E in EC8 Part: 5 [1].

At the end of the calculations, the total acting and resisting actions are summarized and a stability criterion is determined for which $E_{e d} \leq R_{e d}$. This stability design number, (or over-design factor), $N_{s}$, is obtained by

$$
N_{s}=\frac{R_{e d}}{E_{e d}}
$$

where $R_{e d}$ is the overall earthquake design resistance provided by the complete engineering system (wall, soil, anchor). This resistance is calculated by eqn. (6) below.

$$
R_{e d}=\left(\sum F v\right) \tan \delta_{d}+P_{p e d}+T_{d}
$$

in which $\Sigma F_{v}$ represents the sum of the vertical forces acting on the system (weight of backfill soil, concrete weight of wall, seismic vertical component). The value of $E_{e d}$ is the total design effect of actions under seismic conditions and is given by eqn. (7) as

$$
E_{e d}=P_{a e d} \cos \delta_{d}+K_{a e d} q_{d} H
$$

\section{Conclusions}

The present paper focuses on the seismic stability of tall retaining walls with surcharge. The implementation of the Eurocodes and specifically EC8, present a

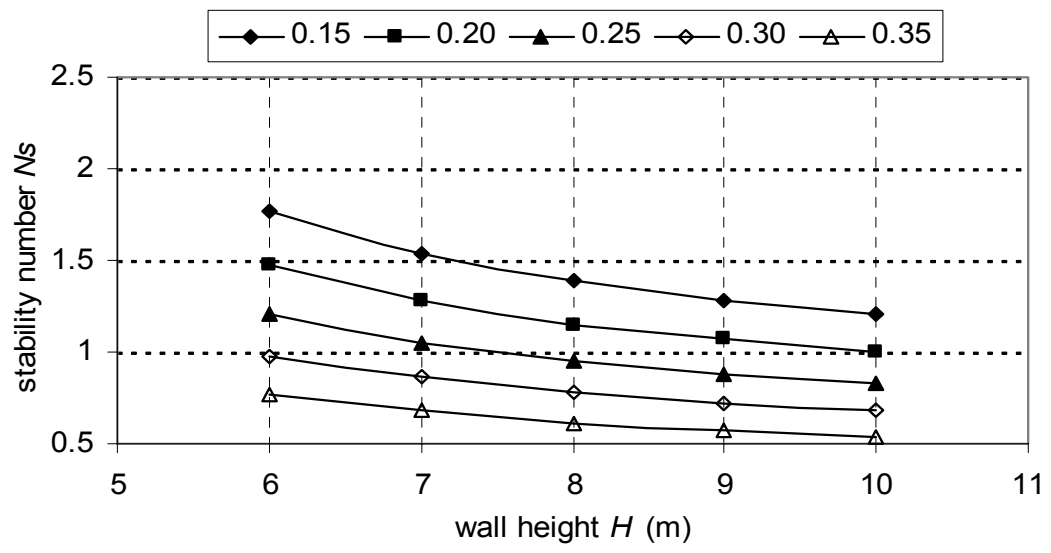

Figure 2: $\quad$ Stability number $N s\left(\gamma=17 \mathrm{kN} / \mathrm{m}^{3}, \varphi=30^{\circ}\right)$. 


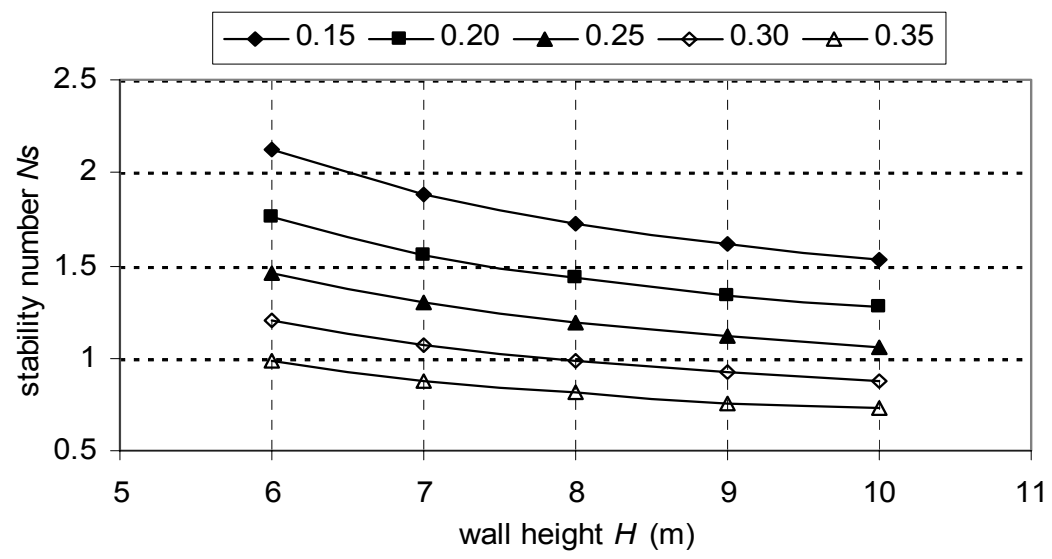

Figure 3: $\quad$ Stability number $N s\left(\gamma=19 \mathrm{kN} / \mathrm{m}^{3}, \varphi=35^{\circ}\right)$.

good opportunity to investigate firstly, the methodology adopted, and secondly, to examine the effects of varying wall heights and increasing seismic motion. A series of analyses were performed in order to assess the sliding stability of a tall retaining wall under the GEO ULS check for sliding resistance. The methodology was based on EC8: Part 5 [1].

The present work shows that Eurocode 8 provides a simplified and quick method for assessing the seismic resistance of retaining walls. However, care needs to be taken in the selection of the partial factors according to the appropriate Design Approach, with relevance to the GEO and STR requirements. A spreadsheet calculation algorithm has been developed and implemented for a series of analyses (selected results are shown in table 2). The results are presented in figs. 2 and 3 giving a good reference guides for the variation of stability number $N_{s}$ for different wall heights and increasing seismicity.

As can be seen from fig. 2, the looser backfill of $\gamma=17 \mathrm{kN} / \mathrm{m}^{3}$ and $\varphi=30^{\circ}$, cannot withstand severe ground movements and will require stronger anchoring forces $(>150 \mathrm{kN} / \mathrm{m})$. For seismicity of $k_{h}=0.25$, the walls become unstable when the height exceeds the critical value of $7.5 \mathrm{~m}$. Good compaction provides a much improved earthquake resistant retaining structure as shown in fig. 3. The wall height of $6 \mathrm{~m}$ provides high values of the stability number $N_{s}$, and this is also true for higher seismicity $\left(k_{h}=0.30\right)$, as opposed to the lower density fill. Furthermore, for higher seismic movement, the reduction of $N_{s}$ is smoother.

It should also be pointed out that some limitations are present. The method recommended by EC8: Part 5 [1] assumes that movement of the wall has occurred so that the active and passive earth pressures have been mobilized. This is what has been considered here, but it relates to the amount of wall displacement that is beyond the scope of the present work. Furthermore, the adverse vertical seismic movement has not been taken into account, although this may have significantly less effect for dry backfills, as observed by Yang and Lung [14]. 
It is anticipated that future work will involve a methodology for undrained, cohesive backfills, and a study of the effects of pore water pressure behind the wall. Additional ULS criteria can be investigated, for example the derivation of an overturning stability factor (EQU check) or the structural resistance of the stem (STR check).

\section{References}

[1] Eurocode 8 EN1998-5: Design of structures for earthquake resistance. Part 5: Foundations, retaining structures and geotechnical aspects, 2004.

[2] Eurocode 7 EN1997-1: Geotechnical design Part 1: General rules, 2004.

[3] Bowles, J., Foundation analysis and design, McGraw Hill, pp. 683-686, 1996.

[4] Frank, R., Bauduin, C., Driscoll, R., Kavvadas M., Krebs Ovesen, N, Orr, T. \& Schuppener B., Retaining Structures (Chapter 9). Designer's Guide to EN 1997-1. Eurocode 7: Geotechnical design Part 1: General rules, series ed. H. Gulvanessian, Thomas Telford, pp. 145-184, 2004.

[5] Sica, S., Santucci de Magistris, F. \& Vinale, F., Seismic behaviour of geotechnical structures, Annals of Geophysics, 45(6), pp. 799-815, 2002.

[6] Choudhury, D., Sitharam, T.G. \& Subba Rao, K.S., Seismic Design of earth retaining structures and foundations, Current Science (Special Section: Geotechnics and Earthquake Hazards), 87(10), pp. 1417-1425, 2004.

[7] Koseki, J., Tatsuoka, F., Munaf, Y., Tateyama, M. \& Kojima, K., A modified procedure to evaluate active earth pressure at high seismic loads, Soils and Foundations (Special Issue on Geotechnical Aspects of the Hyogoken-Nambu Earthquake), 2, pp. 209-216, 1998.

[8] Reynolds, C.E. \& Steedman, J.C., Loads (Chapter 9), Reinforced Concrete Designer's Handbook, pp. 119-121, Spon Press, 2003.

[9] Simpson, B. \& Driscoll, R., Eurocode 7 - a commentary. Construction Research Communication, Watford, 1998.

[10] Caltabiano, S., Cascone, E. \& Maugeri, M., Seismic stability of retaining walls with surcharge, Soil Dynamics and Earthquake Engineering, 20(5-8), pp. 469-476, 2000.

[11] National Annex to CYS EN1997-1 Eurocode 1: Geotechnical Design Part 1: General rules, 2004.

[12] Fardis, M.N., Carvalho, E., Alnashai, A., Faccioli, E., Pinto, P. \& Plumier, A., Foundations, retaining structures and geotechnical aspects (Chapter 10). Designer's Guide to EN 1998-1 and 1998-5. Eurocode 8: Design Provisions for Earthquake Resistant Structures, Thomas Telford, 2004.

[13] National Annex to CYS EN1998-5 Eurocode 8: Design of structures for earthquake resistance. Part 5: Foundations, retaining structures and geotechnical aspects, 2004.

[14] Yang, J. \& Lung, W.H., Seismic design of retaining walls considering vertical ground acceleration, Proceedings of $4^{\text {th }}$ International Conference on Earthquake Geotechnical Engineering, Thessaloniki, 2007. 